\title{
¿S Research Square

\section{Biotransformation in Combination of Traditional Medicinal Plants: The Effect of Wickerhamomyces Anomalus on the Antidiabetic Potential and Metabolite Profiling}

Praveen Kumar Gaur ( $\nabla$ gaurmpharm@rediffmail.com )

ITS College of Pharmacy https://orcid.org/0000-0002-4221-1485

Sadish Kumar Shanmugam

ITS College of Pharmacy

Research

Keywords: $F$

Posted Date: August 11th, 2020

DOl: https://doi.org/10.21203/rs.3.rs-47504/v2

License: (c) (1) This work is licensed under a Creative Commons Attribution 4.0 International License.

Read Full License 
The authors have withdrawn this preprint from Research Square 